\title{
Kinetyka PSA u pacjentów z rakiem gruczołu krokowego leczonych hipofrakcjonowana radioterapią stereotaktyczną SBRT
}

\section{PSA kinetics in prostate cancer patients treated with Stereotactic Body Radiotherapy (SBRT)}

\author{
Marek Konkol ${ }^{1}$ \\ ${ }^{1}$ Oddział Radioterapii Onkologicznej I z Izba Przyjęć, Wielkopolskie Centrum Onkologï, Poznań, Polska
}

\begin{abstract}
Streszczenie
Antygen Specyficzny dla Prostaty (ang. Prostate-specific antygen, PSA) pozostaje najlepszym biomarkerem do monitorowania pacjentów z rakiem prostaty po zakończeniu radykalnego leczenia. Kinetyka jego spadku oraz osiągane najniższe wartości (tzw. nadiry) podlegały licznym badaniom w klasycznej radioterapii oraz brachyterapii, sugerując ich znaczenie jako ważnych czynników prognostycznych. W dobie rozwoju radioterapii stereotaktycznej, hipofrakcjonowanej, istotne jest zrozumienie zachowania PSA po tej formie leczenia. Praca prezentuje aktualne dane literaturowe w tym zakresie wykazujace charakterystyczna kinetykę spadku PSA (gwałtowny spadek w 1 roku oraz dalszy, wolniejszy w latach kolejnych) oraz wysokie odsetki nadirów PSA <0.5 ng/ml (ponad 70\%). Prace ukazują także dość częste (ok 30-40\%) występowanie zjawiska odbicia PSA (tzw. PSA bounce) analogicznie do brachyterapii.
\end{abstract}

\begin{abstract}
Prostate-specific antigen (PSA) remains the best biomarker for a follow-up of prostate-cancer patients after a radical treatment. Its kinetics and nadirs have been well described in many papers on conventional EBRT and brachytherapy suggesting its importance as good prognostic factors. In the era of extremely hypofractionated stereotactic body radiotherapy, it is important to understand how PSA changes after this method of treatment. The paper presents the present literature on this issue describing the specific slope characteristics (rapid after the $1^{\text {st }}$ year and slower in the following years) and high percentage of nadirs $<0.5$ $\mathrm{ng} / \mathrm{ml}$ (above 70\%). The common (30-40\%) phenomenon of PSA bounce is also described which is similar to brachytherapy.
\end{abstract}

Adres do korespondencji

Marek Konkol

Oddział Radioterapii Onkologicznej I z Izbą Przyjęć

Wielkopolskie Centrum Onkologii, ul. Garbary 15, 61-866 Poznań, Polska

Telefon. +48 618850867; Fax. +48 618850935

e-mail: marek.konkol@wco.pl 
Stowa kluczowe: Prostate-specific antygen, PSA, kinetyka PSA, zmiana PSA po radioterapii, nadir PSA, Stereotactic Body Radiotherapy, SBRT, CyberKnife

Keywords: Prostate-specific antigen, PSA, PSA kinetics, Post-radiotherapy PSA change, PSA nadir, Stereotactic Body Radiotherapy, SBRT, CyberKnife

\section{Wstęp}

Rak prostaty pozostaje niezmiennie istotnym problemem klinicznym utrzymując się na drugim miejscu pod względem zachorowalności na nowotwory złośliwe wśród mężczyzn zarówno w Polsce, jak i na świecie [1-2]. W przypadku tak licznej grupy pacjentów oraz mnogości opcji terapeutycznych, kluczowe są skuteczne metody kontroli chorych po zakończonym leczeniu. W przypadku raka gruczołu krokowego PSA (ang. prostate-specific antygen - Antygen Specyficzny dla Prostaty) jest najlepiej poznanym i szeroko opisanym biomarkerem, przydatnym w monitorowaniu odpowiedzi na leczenie i wczesnym rozpoznaniu wznowy.

U pacjentów niepoddanych leczeniu hormonalnemu (ang. Androgen Deprivation Therapy, ADT) kinetyka PSA najdokładniej odzwierciedla efekt biologiczny promieniowania jonizującego. Stąd liczne badania nad zmianami PSA u pacjentów leczonych klasyczną radioterapią z pól zewnętrznych, jak i brachyterapią. [3]

W leczeniu raka prostaty coraz większą rolę odgrywa ekstremalnie hipofrakcjonowana radioterapia SBRT (ang. Stereotactic Body RadioTherapy), a dojrzewający materiał kliniczny ukazuje bardzo zadowalające wyniki onkologiczne [4]. Choć uzyskujemy coraz więcej danych pomagających zrozumieć zmiany PSA po tej formie napromieniania, ciągle istnieje wiele niewiadomych.

\section{Kinetyka PSA w klasycznej radioterapii}

W klasycznej radioterapii, niższa wartość minimalna PSA osiągnięta po zakończeniu leczenia (tzw. nadir PSA) oraz krótszy czas jej osiągnięcia wydaje się wiązać się z lepszymi wynikami leczenia. [5-8]. Wiele współczesnych prac sugeruje istotną poprawę w zakresie cDFS (ang. clinical Disease Free Survival) przy osiągnięciu ostatecznego nadiru poniżej $0,5 \mathrm{ng} / \mathrm{ml}$ [9-10], czy choćby nadiru po pierwszym roku poniżej 4ng/ml [11]. Temat ten jednak nadal budzi wiele kontrowersji, gdyż istnieją przekonujące prace zarówno potwierdzające [12-13], jak i negujące tempo spadku PSA jako istotnego klinicznie predyktora [14-15].

W przypadku brachyterapii w kinetyce PSA szczególnie zaznaczone jest odbicie PSA (tzw. PSA bounce), czyli przejściowy wzrost PSA po zakończeniu napromieniania, niebędący wynikiem niepowodzenia leczenia. W zależności od przyjętej definicji, występuje u 17-46\% chorych w ciągu pierwszych 3 lat obserwacji. [16-18]. Najczęściej nie przekracza on $1 \mathrm{ng} / \mathrm{ml}$ i ustępuję w ciągu poniżej roku [17]. W pracy Haucka i wsp [19] wykazano wpływ rodzaju frakcjonacji w brachyterapii HDR (ang. High Dose Rate) na częstotliwość występowania tego zjawiska - pacjenci leczenie jedną frakcją 19Gy doświadczali PSA bounce istotnie częściej od pacjentów leczonych schematami frakcjonowanymi.

\section{Kinetyka PSA w radioterapii SBRT}

W kontekście powyższych opracowań ciekawe pozostaje zrozumienie kinetyki PSA w radioterapii SBRT. W tych wysoce hipofrakcjonowaych schematach najczęściej stosuje się dawkę 36,25Gy w 5 frakcjach lub 38 Gy w 4 frakcjach, naśladując dobrze poznany schemat brachyterapii HDR.

Anwari wsp. [20] porównał 75 pacjentów z grup niskiego i pośredniego ryzyka leczonych konwencjonalnym schematem frakcjonowania (70.2- 76Gy) z 43 pacjentami leczonymi radioterapią SBRT (38Gy/4fx). Mediana nadiru PSA i spadku dla klasycznej EBRT (External Beam Radiotherapy - klasyczna radioterapia z pól zewnętrznych) wyniósł 1.00, 0.72 i $0.60 \mathrm{ng} / \mathrm{ml}$ oraz -0.09, -0.04, -0.02 ng/ml/m-c, odpowiednio dla 1, 2 i 3 -letniego okresu po RT. Dla SBRT natomiast, mediany nadirów PSA i spadku wyniosły odpowiednio 0.70, 0.40, $0.24 \mathrm{ng}$ oraz -0.09, -0.06, -0.05 ng/ml/m-c, dla tych samych okresów obserwacji. Spadki PSA po 2 i 3 roku były istotnie większe dla SBRT ( $<$ 0.05). W tych samych okresach nadir PSA dla SBRT był istotnie niższy ( $<$ 0.005). W grupie SBRT u 12\% odnotowano PSA bounce, dla EBRT odsetek ten wynosił zaledwie 9\%. 
W pracy Phak $i$ wsp. [21] przeanalizowano grupę pacjentów leczonych SBRT w najpopularniejszym schemacie 36,25Gy/5fx. Mediana spadku PSA okazała się wyższa niż w poprzednim badaniu i wynosiła odpowiednio $0.359,0.199$ i $0.127 \mathrm{ng} / \mathrm{mL} / \mathrm{m}-\mathrm{c}$ dla okresu of 1, 2 i 3 lat po radioterapii. Mediana nadiru PSA wyniosła $0.27 \mathrm{ng} / \mathrm{mL}$ (mediana czasu: 33 miesiące), a ponad 70\% pacjentów osiągnęło nadir poniżej o,5 ng/ ml. Warto zwrócić uwagę, iż u 36\% pacjentów odnotowano PSA bounce (mediana czasu do wystąpienia: 13 miesięcy). 5-letni przeżycie bez wznowy biochemicznej wyniósł 100\% dla obu grup ryzyka progresji. Park i wsp. [22], również u pacjentów w populacji koreańskiej, w tym samym schemacie leczenia raportuje nieco wolniejszy spadek PSA (Tabela 1.)

Tabela 1. Porównanie szybkości spadków PSA (podano mediany). b.d. - brak danych

\begin{tabular}{|c|c|c|c|c|}
\hline & Anwar i wsp. [2o] & Phak i wsp. [21] & Konkol i wsp. [25] & Park i wsp. [22] \\
\hline Spadek w I roku & $-0.09 \mathrm{ng} / \mathrm{ml} / \mathrm{m}-\mathrm{c}$ & $-0.359 \mathrm{ng} / \mathrm{ml} / \mathrm{m}-\mathrm{c}$ & $-0.46 \mathrm{ng} / \mathrm{ml} / \mathrm{m}-\mathrm{ce}$ & $-0.20 \mathrm{ng} / \mathrm{ml} / \mathrm{m}-\mathrm{c}$ \\
\hline Spadek w II roku & $-0.06 \mathrm{ng} / \mathrm{ml} / \mathrm{m}-\mathrm{c}$ & $-0.199 \mathrm{ng} / \mathrm{ml} / \mathrm{m}-\mathrm{c}$ & b.d. & $-0.03 \mathrm{ng} / \mathrm{ml}$ \\
\hline Spadek w III roku & $-0.05 \mathrm{ng} / \mathrm{ml} / \mathrm{m}-\mathrm{c}$ & $-0.127 \mathrm{ng} / \mathrm{ml} / \mathrm{m}-\mathrm{c}$ & b.d. & b.d. \\
\hline
\end{tabular}

Kole i wsp. [23] przebadał zmiany PSA w grupie 175 pacjentów napromienianych w analogicznym schemacie 36,25Gy/5fx. Wykazano podobną kinetykę spadku z gwałtownym zmniejszeniem wartości w pierwszym roku i wolniejszym w kolejnych latach oraz niemal identyczne wyniki dotyczące nadiru - u ponad 70\% pacjentów wynosił poniżej $0,5 \mathrm{ng} / \mathrm{ml}$ (mediana nadiru $0,3 \mathrm{ng} / \mathrm{ml}$ ), a mediana czasu do jego osiągnięcia wynosiła 30 miesięcy. Podobnie jak poprzednio, ponad 36\% pacjentów doświadczyło PSA bounce, a mediana czasu jego wystąpienia wyniosła 15 miesięcy. U 12 pacjentów wystąpił wzrost poziomu PSA spełniający kryteria wznowy biochemicznej według kryteriów Phoenix, jednak co istotne, u 6 z nich okazał się przejściowy (zaliczony jako PSA bounce, bez interwencji klinicznych) i ulegał ponownemu spadkowi ustanawiając nowy nadir.

Katariaiwsp. [24] w najdłuższym z dotychczas publikowanych, 5-letnim okresie obserwacji u 145 pacjentów (65 z grupy niskiego i 80 z grupy pośredniego ryzyka progresji) leczonych w schemacie 35-37.5Gy/5fx uzyskuje zbliżone wartości osiąganych nadirów. Aż 84\% pacjentów osiąga wartość <0,5 ng/ml, a 37\% wartość < 0,2 ng/ml, którą uznaje się za wartość ablacyjną. Jedynymi predyktorami osiągnięcia wartości poniżej o,2 ng/ ml okazały się wyjściowy poziom PSA oraz wartość nadiru testosteronu. 40\% pacjentów doświadczyło PSA bounce, a u ok. 10\% z nich spełniał on kryteria wznowy biochemicznej wg definicji Phoenix. 5-letnie odsetki bez wznowy biochemicznej wyniosły 98,5\% i 95\% odpowiednio dla grupy niskiego i pośredniego ryzyka progresji. (Tabela 2.)

Tabela 2. Osiągane nadiry PSA oraz PSA bounce (podano mediany). b.d. - brak danych

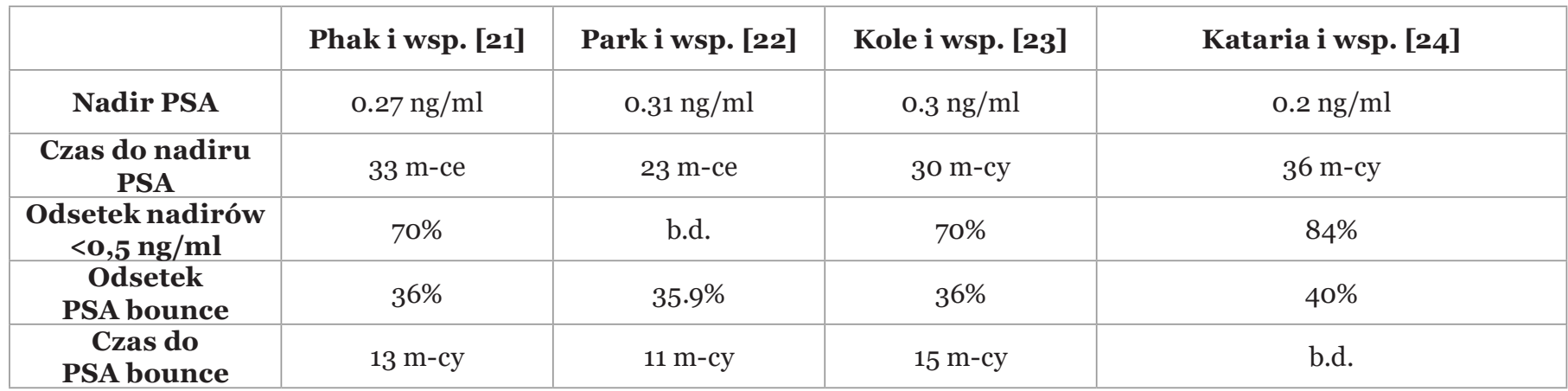

W opracowaniu własnego materiału autora [25] przedstawiono wstępne dane obejmujące 12 miesięczny okres obserwacji u 44 pacjentów leczonych schematem 5x7,25Gy. Mediana spadku PSA wynosiła o,46ng/ml/ $\mathrm{m}-\mathrm{c}$, a mediana osiąganego u pacjentów nadiru PSA po 12 miesiącach wyniosła 1,26 ng/ml. Są to dane zbliżone 
do przytoczonych wcześniej. Warto jednak zauważyć, że w badanej grupie nie odnotowano PSA bounce podczas całego 1-rocznego okresu obserwacji. Uwagę zwraca także duży wzrost PSA między wartościami wyjściowymi sprzed leczenia a końcem napromieniania - średnio pacjenci kończyli napromienianie z wartością 11,89 ng/ml co stanowiło 155\% średniej wartości wyjściowej.

\section{Podsumowanie}

We wszystkich wspomnianych pracach odnotowano podobną kinetykę spadku PSA po zastosowaniu radioterapii SBRT z gwałtownym spadkiem w pierwszym roku i dalszym, wolniejszym w latach kolejnych. Analogicznie do brachyterapii HDR stwierdzono wystąpienie PSA bounce, najczęściej po okresie ok. 12 miesięcy. Warto zwrócić uwagę, że niektórzy badacze w swoich seriach odnotowali nawet 3-krotne odbicie [26], a ryzyko jego wystąpienia zwiększało się wraz ze wzrostem wielkości napromienianego gruczołu krokowego. Wszystkie prace udowodniły występowanie nadiru poniżej o,5 ng/ml u ponad 70\% pacjentów. Praca z najdłuższym okresem obserwacji wykazała 40\% z nadirem <0,2 ng/ml uznawanym za wartość ablacyjną. Ciągle jest to jednak wartość niższa niż opisywana w brachyterapii, gdzie w niektórych badaniach opisywane są mediany nadirów wynoszące $0,1 \mathrm{ng} / \mathrm{ml}$ [27] czy nawet 0,05 ng/ml [28]. Trzeba jednak pamiętać, że okres obserwacji w SBRT dłuższy niż 5 lat może przynieść dalsze spadki obserwowanych nadirów. Dodatkowo przy tak niskich wartościach PSA należy zwrócić uwagę na metodologię oznaczania tego biomarkera - w pracy Katarii i wsp. ultraczułe testy zostały użyte jedynie u części pacjentów, co mogło wpłynąć na zawyżenie prezentowanych wartości w zakresach oscylujących ok o,1 ng/ml (najniższa mierzalna wartość w standardowych testach). W miarę dalszego dojrzewania materiału klinicznego, można spodziewać się wykazania radioterapii SBRT jako skutecznej i bezpieczniej metody leczenia raka prostaty.

\section{Konflikt interesu / Conflict of interest}

Nie występuje / None

\section{Finansowanie / Financial support}

Powyższa praca oraz badanie [25] zostały sfinansowane w ramach grantu Wielkopolskiego Centrum Onkologii w Poznaniu nr 5/2016 (120)

\section{Piśmiennictwo / References}

[1] Krajowy Rejestr Nowotworów, Dane epidemiologiczne za rok 2013, www.onkologia.org.pl, dostęp: sierpień 2017

[2] World Cancer Report 2014. International Agency for Research on Cancer, World Health Organization. 2014. ISBN 978-92-832-0432-9

[3] Kaplan ID, Cox RS, Bagshaw MA, A model of prostatic carcinoma tumor kinetics based on prostate specific antigen levels after radiation therapy, Cancer 68 (1991) 400-405.

[4] Katz A, Kang J, Stereotactic Body Radiation Therapy for Low-, Intermediate-, and High-Risk Prostate Cancer: Disease Control and Quality of Life at 6 Years, Int J Radiat Oncol Biol Phys 2013;87:S24-5

[5] Lee WR, Hanlon AL, Hanks GE, Prostate specific antigen nadir following external beam radiation therapy for clinically localized prostate cancer: the relationship between nadir level and disease-free survival, J. Urol. 156 (1996) 450-453.

[6] Pollack A, Zagars GK, Antolak JA, Kuban DA, Rosen II, Prostate biopsy status and PSA nadir level as early surrogates for treatment failure: analysis of a prostate cancer randomized radiation dose escalation trial, Int. J. Radiat. Oncol. Biol. Phys. 54 (2002) 677-685.

[7] Shipley WU, Thames HD, Sandler HM, et al., Radiation therapy for clinically localized prostate cancer: a multi-institutional pooled analysis, JAMA 281 (1999) 1598-1604.

[8] Zietman AL, Tibbs MK, Dallow KC, Smith CT, Althausen AF, Zlotecki RA, et al., Use of PSA nadir to predict 
subsequent biochemical outcome following external beam radiation therapy for T1-2 adenocarcinoma of the prostate, Radiother. Oncol. 40 (1996) 159-162.

[9] Zietman AL, Tibbs MK, Dallow KC, Smith CT, Althausen AF, Zlotecki RA, et al., Use of PSA nadir to predict subsequent biochemical outcome following external beam radiation therapy for T1-2 adenocarcinoma of the prostate, Radiother. Oncol. 40 (1996) 159-162.

[10] Ray ME, Thames HD, Levy LB, Horwitz EM, Kupelian PA, Martinez AA, et al., PSA nadir predicts biochemical and distant failures after external beam radiotherapy for prostate cancer: a multiinstitutional analysis, Int. J. Radiat. Oncol. Biol. Phys. 64 (2006) 1140-1150.

[11] Cheung R, Tucker SL, Kuban DA. First-year PSA kinetics and minima after prostate cancer radiotherapy are predictive of overall survival. int J Radiat oncol Biol Phys 2006;66: 20-4.

[12] Chauvet B, Félix-Faure C, Lupsascka N, et al., Prostate-specific antigen de- cline: a major prognostic factor for prostate cancer treated with radiation therapy, J. Clin. Oncol. 12 (1994) 1402-1407.

[13] Ritter M, Messing E, Shanahan T, Potts S, Chappell R, Kinsella T, Prostate specific antigen as a predictor of radiotherapy response and patterns of failure in localized prostate cancer, J. Clin. Oncol. 10 (1992) 1208-1217. Zagars GK, Pollack A, The fall and rise of prostate-specific antigen: kinetics of serum prostate-specific antigen levels after radiation therapy for prostate cancer, Cancer 72 (1993) 832-842.

[15] Zagars GK, Pollack A, Kinetics of serum prostate-specific antigen after ex- ternal beam radiation for clinically localized prostate cancer, Radiother. Oncol. 44 (1997) 213-221.

[16] [16]. Patel N, Souhami L, Mansure JJ, et al. Prostate-specific antigen bounce after high-dose-rate prostate brachytherapy and hypo- fractionated external beam radiotherapy. Brachytherapy 2014;13: 450-455.

[17] [17]. Ciezki JP, Reddy CA, Garcia J, et al. PSA kinetics after prostate brachytherapy: PSA bounce phenomenon and its implications for PSA doubling time. Int J Radiat Oncol Biol Phys 2006;64:512-517.

[18] [18]. Stock RG, Stone NN, Cesaretti JA. Prostate-specific antigen bounce after prostate seed implantation for localized prostate cancer: De- scriptions and implications. Int J Radiat Oncol Biol Phys 2003;56: 448-453.

[19] Hauck CR, Ye H, Chen PY, Gustafson GS, Limbacher A, Krauss DJ, Increasing Fractional Doses Increases the Probability of Benign PSA Bounce in Patients Undergoing Definitive HDR Brachytherapy for Prostate Cancer, Int J Radiation Oncol Biol Phys, Vol. 98, No. 1, pp. 108e114, 2017

[20] Anwar M, Weinberg V, Chang AJ, Hsu IC, Roach M, Gottschalk A, Hypofractionated SBRT versus conventionally fractionated EBRT for prostate cancer: comparison of PSA slope and nadir, Radiation Oncology 2014, 9:42

[21] Phak JH, Kim HJ, Kim WC, Prostate-specific antigen kinetics following hypofractionated stereotactic body radiotherapy for low- and intermediate-risk prostate cancer, Cancer Treatment Communications 5 (2016) 46-50

[22] Park YH, Choi IY, Yoon SC, Jang HS, Moon HW, Hong SH, et al, Prostate-specific antigen kinetics after primary stereotactic body radiation therapy using CyberKnife for localized prostate cancer, Prostate International 3 (2015) 6 e9

[23] Kole TP, Chen LN, Obayomi-Davies O, Kim JS, Lei S, Suy S, Dritschilo A, Collins SP, Prostate specific antigen kinetics following robotic stereotactic body radiotherapy for localized prostate cancer, Acta Oncologica,2015, 54:6, 832-838,

[24] Kataria S, Koneru H, Guleria S, Danner M, Ayoob M, Yung T, et al, Prostate- Speci c Antigen 5 Years following Stereotactic Body Radiation Therapy for Low- and Intermediate-Risk Prostate Cancer: An Ablative Procedure? Front. Oncol. 2017, 7:157.

[25] Konkol M, Galuba A, Milecki P, Skrobala A, Jodda A, Adamczyk M, Litoborska J, PSA kinetics in prostate cancer patients after SBRT radiotherapy using CyberKnife, Radiotherapy and Oncology, 2016-04-01, Volume 119, Pages S646-S646

[26] Straka CA, Kim D, Cho L, Yan J, Lotan Y, Kavanagh B, et al, Early and Multiple PSA Bounces Can Occur Following High-Dose Prostate Stereotactic Body Radiation Therapy: Subset Analysis of a Phase 1/2 Trial, Int J Radiation Oncol Biol Phys Volume 90 Number 1S, Supplement 2014

[27] Zelefsky MJ, PSA bounce versus biochemical failure following prostate brachytherapy. Nat Clin Pract Urol (2006) 3(11):578-9. 
[28] Lo AC, Morris WJ, Lapointe V, Hamm J, Keyes M, Pickles T, et al. Prostate- specific antigen at 4 to 5 years after low-dose-rate prostate brachytherapy is a strong predictor of disease-free survival. Int $\mathrm{J}$ Radiat Oncol Biol Phys (2014) 88(1):87-93. 